\title{
Barium granuloma of the transverse colon
}

\author{
P. H. MCKeE \\ C. H. S. CAMERoN
}

The Department of Pathology, Queen's University, Belfast

\begin{abstract}
Summary
A case of barium sulphate granuloma of the transverse colon following gunshot wounds to the abdomen has been described. Scanning electron microscopy with electron probe microanalysis was used to confirm the presence of barium sulphate and the absence of lead or other elements related to the gunshot wounds.
\end{abstract}

\section{Introduction}

Barium sulphate granuloma is a very rare complication of barium enemata. It was first described by Beddoe, Kay and Kaye (1954). Since then, a variety of reports have been published (Levine and Simpson, 1960; Caney and Stephens, 1973; Lewis, Keistein and Koss, 1975). It has been reported as occurring in the appendix (Chant, 1970) and as a complication of bronchography (Mital et al., 1975). The purpose of this paper is to describe a case of barium sulphate granuloma of the transverse colon, occurring as a complication of a gunshot wound to the abdomen.

\section{Clinical summary}

The patient was a 56-year-old male who was admitted to the Royal Victoria Hospital following a gunshot wound to the chest and abdomen. The chest injuries were repaired and, at laparotomy, perforation of the jejunum and laceration of the colon were identified. The perforation and lacerations were sutured and a proximal colostomy performed. The patient made a rapid recovery from his extensive injuries.

However, a barium enema performed 2 months later revealed a stricture of the transverse colon from the distal end of which was a small fistulous tract. Consequent upon this, the area of narrowed colon was removed and the colostomy closed. Since then the patient's condition has been uneventful.

\section{Material and methods}

The specimen of transverse colon taken at laparotomy was fixed in $10 \%$ formaldehyde. Following macroscopic description, blocks were selected and fixed in Bouin's fluid for routine processing. Sections cut from the paraffin wax-embedded blocks were stained with haematoxylin and eosin and examined.
Serial material was obtained from the paraffin wax blocks and processed for routine X-ray micros analysis in the scanning electron microscoper (Cameron and McKee, 1978).

The specimens were examined in a Cambridge Instrument S-600 Stereoscan Electron Microscope equipped with a link X-ray microprobe analysise system utilizing a Kevex $\mathrm{Si}(\mathrm{Li})$ detector. Operationad voltage was $20 \mathrm{kV}$. Photographic records werE़ obtained using Polaroid $3^{3} / 4 \times 4^{3} / 4$ land pack type 105 and Ilford Fp. 435 mm film.

\section{Results}

The gross specimen consisted of $12 \mathrm{~cm}$ of large intestine. Approximately $5 \mathrm{~cm}$ from one limit was an area of stricture formation. Arising from this pass a $1.0 \mathrm{~cm}$-long fistulous tract. Histological examinaco tion of sections taken from this area reveale normal mucosa and muscle coat. However, there was quite marked submucosal and serosal fibrosis? In addition, in the serosa numerous macrophages were seen containing greenish crystalloid materiat (Figs 1 and 2).

When viewed in the scanning electron microscopepos the tissue structure was easily recognized and com parable to that observed in histological section (Fig 3 ). An area of high electron activity was observed. This area showed little detail when examined at us to $\times 1000$ magnification (Fig. 4). Microprobe. analysis of this and similar areas revealed counts as shown in Table 1. The count time used was 100 . seconds.

TABLE 1. Teletype print-out of typical energy spectrum $\frac{\mathrm{D}}{\mathrm{O}}$

\begin{tabular}{|c|c|c|}
\hline Energy (eV) & Integral & Element \\
\hline $1 \cdot 48$ & 1041 & Al \\
\hline 1.72 & 335 & $\mathbf{S i}$ \\
\hline $2 \cdot 26$ & 53224 & $\mathbf{S}$ \\
\hline $2 \cdot 62$ & 3311 & $\mathrm{Cl}$ \\
\hline $4 \cdot 44$ & 36845 & $\mathbf{B a}$ \\
\hline $4 \cdot 84$ & 13399 & $\mathrm{Ba}\left(\mathrm{B}_{1}\right)$ \\
\hline $5 \cdot 16$ & 1632 & $\mathrm{Ba}\left(\mathrm{B}_{2}\right)$ \\
\hline $5 \cdot 52$ & 964 & $\mathrm{Ba}\left(\gamma_{1}\right)$ \\
\hline
\end{tabular}




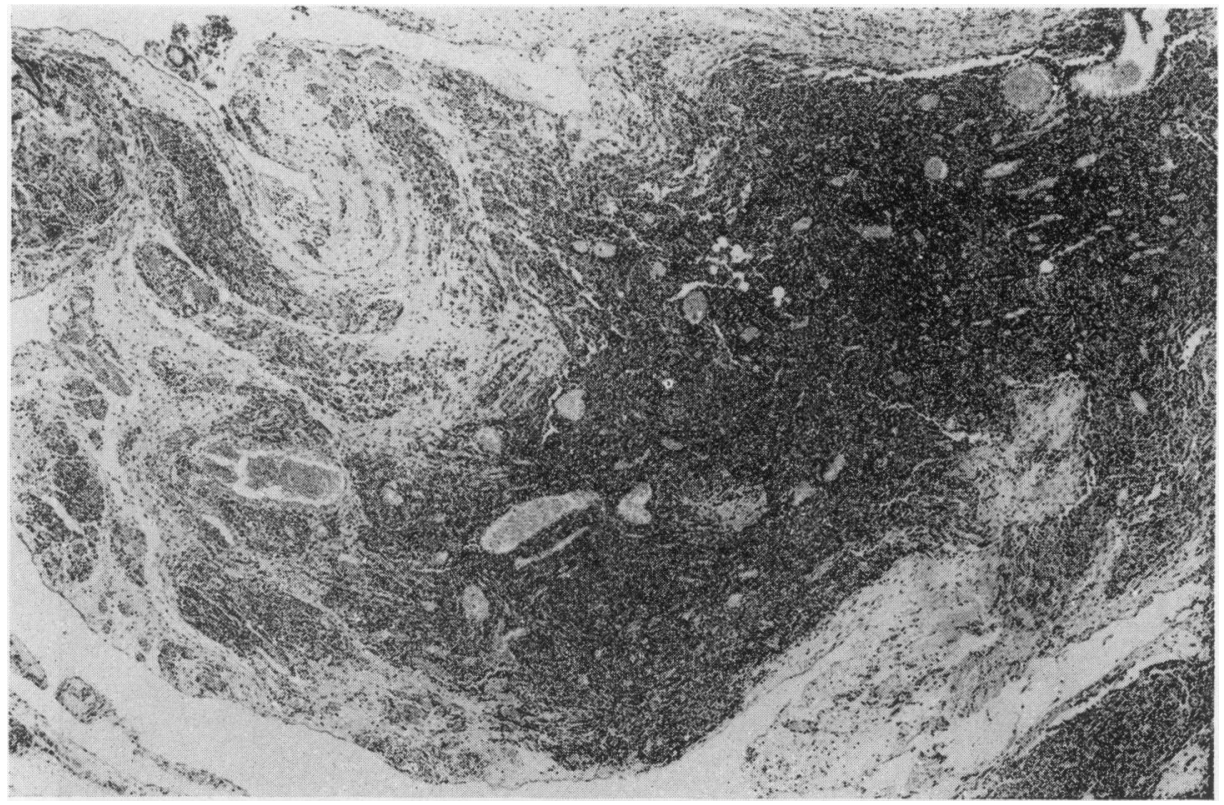

FIG. 1. Low power view of serosal aspect of colon showing the barium granuloma. HE, $\times 32$.

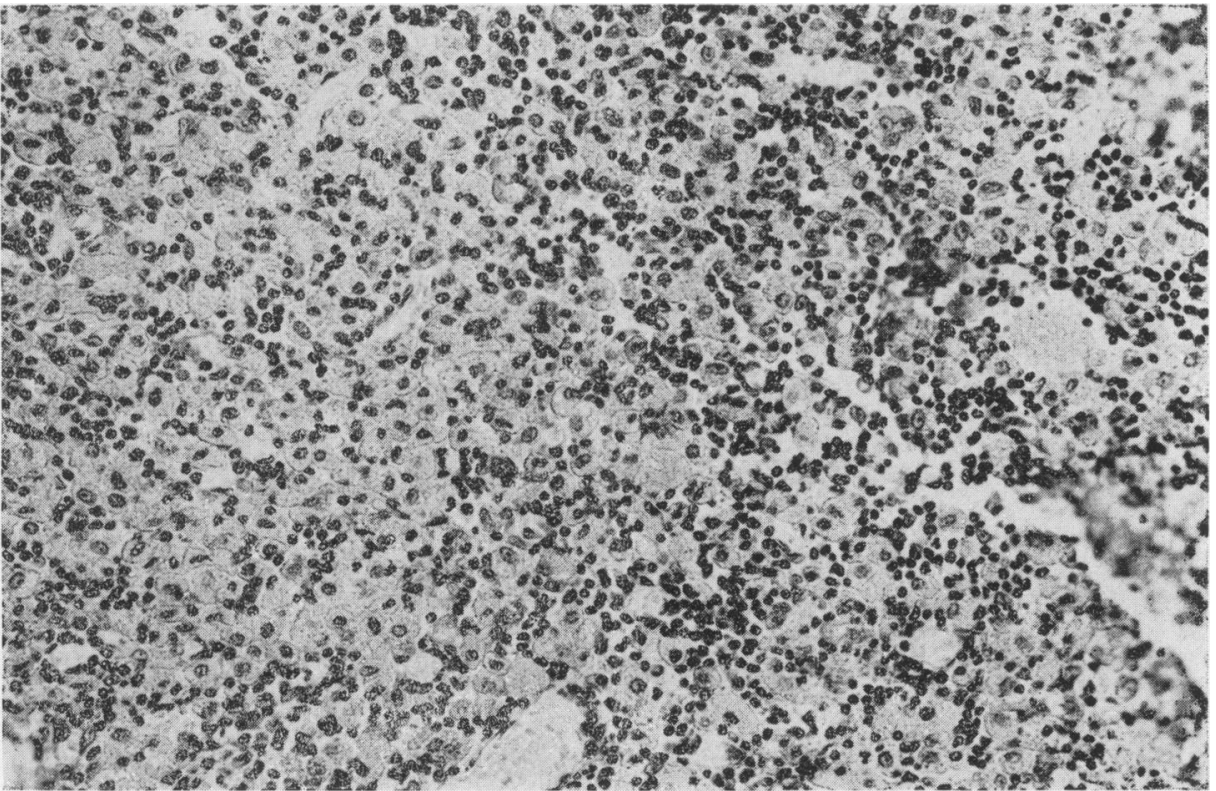

FIG. 2. Higher power to show the macrophages containing granular material. HE, $\times 80$. 


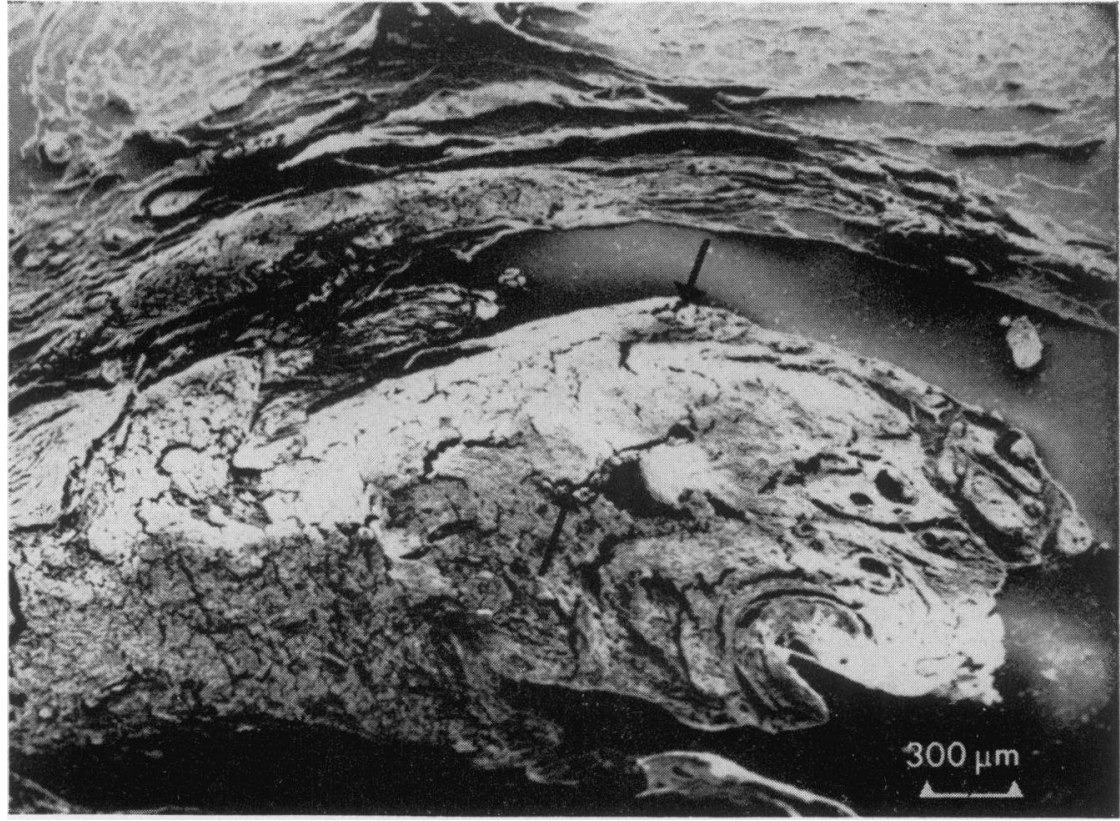

FIG. 3. Consecutive section to Fig. 1 viewed in the scanning electron microscope, $\times 40$.

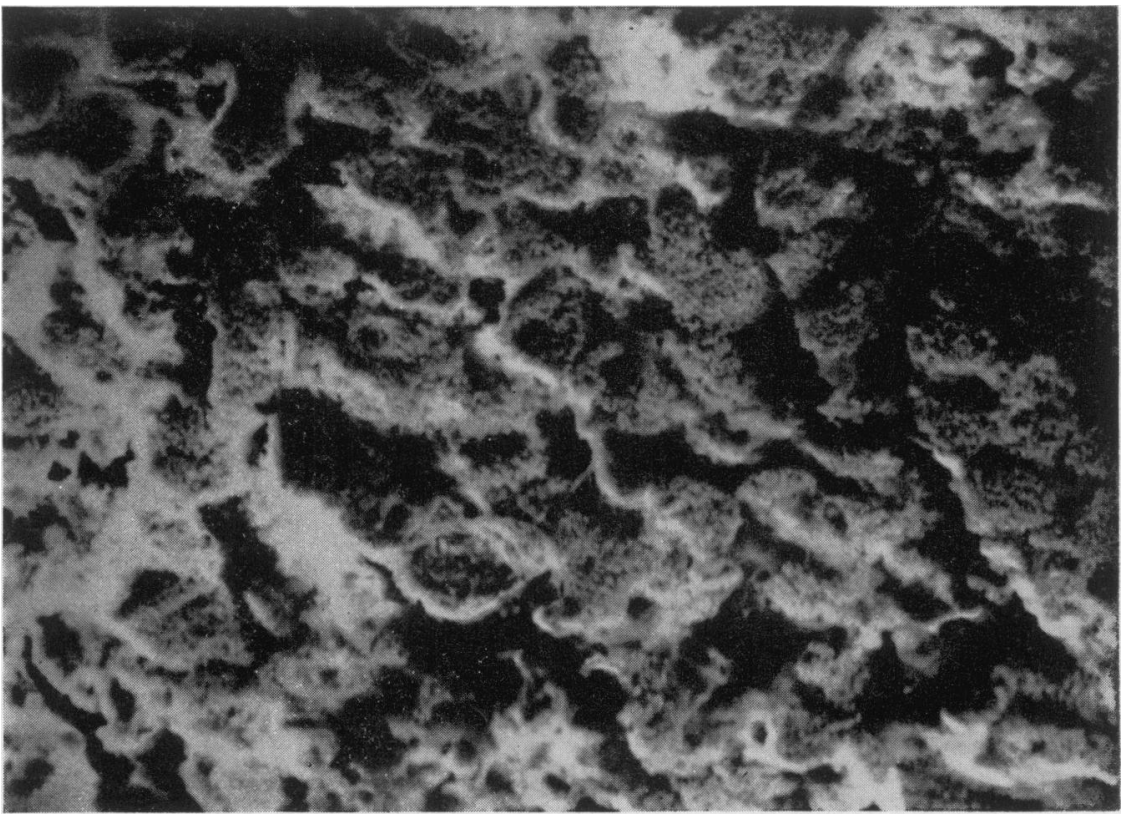

FiG. 4. Higher power of Fig. $3, \times 800$. 


\section{Discussion}

Barium granuloma of the rectum is an exceedingly rare condition. At present, twenty cases have been described in past publications (McDonald and Rowe, 1976).

It has been suggested that previous rectal biopsy, excessive intralumenal pressure, pre-existing disease such as ulcerative colitis, diverticulitis or carcinoma may be predisposing factors in the development of barium granuloma following an enema. Obviously improper or an excessively forceful technique would also be important.

The presence of barium granuloma should not cause any serious clinical problems but if there was excessive fibrosis it might cause some diagnostic difficulties.

As far as the authors are aware, barium granuloma has not been previously described from the transverse colon. This case was of particular interest in that it demonstrated an unusual method of development of such a lesion. It would seem most likely that some barium leaked along the fistulous tract at the site of previous surgery and this became lodged in the serosa of the bowel. Some accompanying fibrosis was seen but as this was located at the site of a fistula this is hardly surprising. In agreement with other workers (Gaston, 1969) the present authors were surprised to see so little reaction.

It is peculiar that this condition should be so rare, considering the numerous occasions when circumstances could predispose to its development. Review of past records in the Department of Pathology, Queen's University, Belfast, reveals only one other case which was associated with diverticulitis of the sigmoid colon. The rarity may be real, or apparent due to failure to recognize the lesion or disinclination to report it.

It was obviously of great importance to identify exactly the nature of the material present in the granuloma. It was considered likely that it did represent barium sulphate from the enema but it was also necessary to exclude any possibility of its being related to any parts of the ammunition that caused the initial wounds. It was for this reason that the tissue was subjected to electronprobe microanalysis.

Under optimum conditions, tissues for elemental analysis would be frozen and unfixed or fixed in either purified glutaraldehyde or para-formaldehyde. The use of such fixatives as Bouin's fluid, which contains approximately $0.015 \%$ sulphur, should be avoided as they introduce contaminants into the tissue. It must be underlined that the choice of Bouin's fluid in this instance was made as a routine histological procedure before any thought was given to microanalysis. However, the addition of such a small percentage of sulphur could not account for the extremely high counts obtained in the tissue.

A round of ammunition consists of a bullet, the cartridge case, the powder and the primer.

Older ammunition contained primers based on mercury fulminate $\left(\mathrm{Hg}(\mathrm{CNO})_{2}\right)$. Nowadays, however, the more modern primer is composed of lead styphnate $\left(\mathrm{C}_{6} \mathrm{H}\left(\mathrm{NO}_{2}\right)_{3} \mathrm{O}_{2} \mathrm{~Pb}\right)$ and barium nitrate $\left(\mathrm{Ba}\left(\mathrm{NO}_{3}\right)_{2}\right)$ with the addition of two or more of the following compounds: tetrazene $\mathrm{C}_{18} \mathrm{H}_{12}$; lead dioxide $\mathrm{PbO}_{2}$; lead hypophosphite $\left(\mathrm{Pb}\left(\mathrm{H}_{2} \mathrm{PO}_{2}\right)_{2}\right.$; antimony sulphide $\mathrm{Sb}_{2} \mathrm{~S}_{3}$; calcium silicide $\mathrm{CaSi}_{2}$; aluminium powder $\mathrm{Al}$.

The powder of a round of ammunition nowadays is composed of organic nitro compounds (smokeless powders).

The powder usually consists of a lead core covered with a gilded metal jacket (copper alloyed with $5-10 \%$ of zinc). This jacket may be bare or plated with tin or, rarely, nickel.

Spectrographic analysis of lead bullets shows the presence of other elements in traces: copper, bismuth, silver and occasionally thallium.

The cartridge case is made in most instances of brass. Within recent years the primer cap at the base of the cartridge has been nickel-plated. Occasionally one also finds that the brass case is nickel-plated.

Firearms discharge-residues consist of powder, primer, lubricants, and metals. Analysis of such residues have shown that the most frequently occurring elements are lead, antimony, barium and copper. If one includes older ammunition, then mercury must be added to the list.

Thus, when a bullet is fired from a gun, it will have residues, from the primer, etc., on its surface. When the bullet penetrates the clothing, skin, etc. of the victim, some of the residues from its surface will be transferred to the perimeter of the bullet hole owing to the wiping action of the clothes, wound margin, etc. Nevertheless it is still possible that on coming to its final rest the bullet still may have a percentage of these substances (residues) on its outer surface.

In the present case, the victim was apparently shot by a rifle and none of the bullets remained within him. It was felt, however, that it was just possible that the 'residues' or even minute fragments of the bullet itself might have at least contributed to the development of the granuloma.

It was for this reason, therefore, that electron probe microanalysis was undertaken.

As can be seen from the results, barium and sulphur were present in very large amounts with much lesser quantities of aluminium and chlorine. Lead, antimony, calcium, copper, tin, nickel, bismuth, silver and thallium were not identified.

Thus, although the presence of barium could be linked with firearms residues, the fact that the other 
commonly found elements, lead, antimony, and copper, were not identified would tend to exclude the possibility of the granuloma being due to residues. Similarly, the absence of lead, copper, zinc, tin, and nickel would exclude the possibility of the granuloma being due to fragments of the bullet.

The presence of aluminium is not as easily explained and it was most likely due to contamination. It may have come from the metallic top of the fixative container or from the specimen stub, although a thick carbon planchet separated the specimen from the surface of the mounting stub.

It was therefore considered that the elements identified could only be attributed to the barium sulphate of the enema.

\section{Acknowledgments}

The authors wish to express their appreciation to $\mathrm{Mr} \mathrm{G}$. Johnston, FRCS, for giving us access to the case. Dr R. H. Williams and Mr A. W. Parke, Department of Physics, New University of Ulster, Coleraine, for generous use of their scanning electron microscope facilities and expert technical assistance.

The authors wish to acknowledge the help given by the Ballistics Division, Department of Industrial and Forensic Science, Ministry of Home Affairs, Northern Ireland.

\section{References}

Beddoe, H.L., KAY, S. \& KAYE, S. (1954) Barium granuloma of the rectum: a report of a case. Journal of the American Medical Association, 154, 747.

Cameron, C.H.S. \& McKee, P.H. (1978) A rapid method for use in the routine histopathological laboratory for the identification of deposits in tissue sections. Irish Medica Laboratory Technology, (in press).

CANEY, J.A. \& STEPHENS, D.H. (1973) Intramural barium (barium granuloma) of colon and rectum. Gastroenter $-\frac{9}{0}$
ology, 65, 316.

Chant, Q.W. (1970) Barium appendicitis. Journal of the Oklahoma State Medical Association, 63, 570.

GASTON, E.A. (1969) Barium granuloma of the rectum Diseases of Colon and Rectum, 12, 241.

Levine, S. \& SimpSon, D.B. (1960) Barium sulphate granu믐 loma of the rectum. American Journal of Proctology, 11 485.

Lewis, J.W., Keistein, M.D. \& Koss, N. (1975) Barium of granuloma of the rectum. An uncommon complication of barium enema. Annals of Surgery, 181, 418.

MCDonald, C.C. \& Rowe, J.R. (1976) Retrorectal fistula் secondary to barium-abscess granuloma. Diseases of Colorbo and Rectum, 19, 71.

Mital, O.P., Narang, R.K., Misra, U.S., Sachan, A.S. \& SAXENA, H. (1975) Barium granuloma following broncho-graphy: A case report. Indian Journal of Chest Diseases $17,55$. 